\title{
Lentiviral expression of anti-microRNAs targeting miR-27a inhibits proliferation and invasiveness of U87 glioma cells
}

\author{
SU Y. FENG ${ }^{1 *}$, CHANG G. DONG ${ }^{2 *}$, WILLIAM K.K. WU ${ }^{3}$, XIAO J. WANG ${ }^{3}$, JIAN QIAO ${ }^{2}$ and JUN F. SHAO ${ }^{1}$ \\ ${ }^{1}$ Department of Neurosurgery, Wuxi People's Hospital of Nanjing Medical University, Wuxi 214023; \\ ${ }^{2}$ Department of Pathophysiology, College of Veterinary Medicine, China Agricultural University, Beijing 100094; \\ ${ }^{3}$ Institute of Digestive Disease, Department of Medicine and Therapeutics and \\ LKS Institute of Health Sciences, The Chinese University of Hong Kong, Hong Kong SAR, P.R. China
}

Received January 29, 2012; Accepted April 25, 2012

DOI: $10.3892 / \mathrm{mmr} .2012 .915$

\begin{abstract}
Glioma is a highly fatal malignant disease and its treatment options are limited. microRNAs represent a novel target for the treatment of cancer. In the present study, we used a lentiviral vector to stably express anti-microRNAs targeting the oncogenic miR-27a in U87 glioma cells. The stable expression of anti-miR-27a significantly reduced the proliferation and increased the accumulation of U87 cells in the sub-G1 phase as determined by Cell Counting kit-8 (CCK-8) assays and flow cytometry, respectively. Results from the Matrigel Transwell assay also indicated that the inhibition of miR-27a substantially impaired the invasiveness of U87 cells. By combining bioinformatic and proteomic approaches, we identified the mRNAs of 8 proteins upregulated in anti-miR-27a-expressing U87 cells as putative direct targets of miR-27a. Collectively, these data suggest that the lentiviral expression of anti-miR$27 \mathrm{a}$ is a feasible approach for the suppression of malignant phenotypes of glioma cells.
\end{abstract}

\section{Introduction}

Glioma, which incurs high mortality due to its fast-growing and invasive nature, is the most frequently encountered intracranial tumor (1). The pathogenesis of glioma is complex and involves the aberrant activation of proto-oncogenes (e.g., EGFR and $I D H 1 / 2)$ and inactivation of tumor suppressor genes (e.g., TP53 and PTEN) (2-4). The causes and consequences of intracellular

Correspondence to: Dr Jun F. Shao, Department of Neurosurgery, Wuxi People's Hospital of Nanjing Medical University, No. 299 Qingyang Road, Wuxi 214023, P.R. China

E-mail: wxbrain@163.com

Dr Jian Qiao, Department of Pathophysiology, College of Veterinary Medicine, China Agricultural University, No. 2 Yuanmingyuan Xi Lu, Beijing 100094, P.R. China

E-mail: qiaojiancau@126.com

*Contributed equally

Key words: microRNA, glioma, lentivirus, proteomics, proliferation signaling network dysregulation in the development of glioma, however, have not yet been fully elucidated. A number of treatment modalities, such as neurosurgery, chemotherapy and radiotherapy, have been devised for gliomas (5). Nevertheless, the prognosis of patients with this malignancy remains dismal, with a median survival time of 9-12 months after diagnosis. This highlights the need to develop novel agents for the treatment of this highly aggressive disease.

microRNA (miRNA) is a class of non-coding RNA. These RNAs, which are of 20-25 nucleotides in length, carry out their biological functions by binding to the 3' untranslated regions (UTRs) of their target mRNAs, thereby repressing the translation of target mRNAs into proteins and/or directly inducing the degradation of target mRNAs (6,7). miRNA genes are first transcribed to primary miRNAs, which are then processed by Drosha into precursor miRNAs. After exportation from the nucleus, precursor miRNAs are further processed by the RNase Dicer to produce miRNA:miRNA* duplexes. The mature miRNA strand then guides the RNA-induced silencing complex to the target mRNA to repress its expression $(7,8)$. miRNA is emerging as a novel player in tumorigenesis. In this regard, miRNA expression is dysregulated in most, if not all, types of cancer. In glioma tissues, the aberrant upregulation of miR-15b (9), miR-21 (10), miR-221/222 (11) and miR-296 (6), and the downregulation of miR-7 (12), miR-124 (13), miR-128 (14), miR-137 (15) and $\mathrm{miR}-181 \mathrm{a} / \mathrm{b} / \mathrm{c}(16,17)$ have been reported. Notably, the restoration of these dysregulated miRNAs to normal expression levels has been shown to impair the growth and survival of glioma cells. These findings support that miRNAs play important functional roles in cancer development. Thus, miRNA represents a novel target for the treatment of glioma.

In the present study, we employed a novel miRNA targeting approach using a lentiviral vector to deliver anti-miRNAs into glioma cells. This vector was constructed to produce short hairpin RNAs, which eventually give rise to short, singlestranded anti-miRNAs that competitively bind to and inhibit endogenous miR-27a, a miRNA that displays oncogenic properties in many types of solid tumors, including breast (18), gastric (19), colon (20) and pancreatic cancers (21). miR-27a has also been shown to be expressed in glioma cells and is detectable in glioma-secreted exosomes (22). In this study, we provide evidence that targeting miR-27a by the lentiviral expression of 
anti-miRNAs substantially impairs the malignant phenotypes of glioma cells. Moreover, coupled with computational prediction and proteomic analysis, we successfully identified the targets specifically repressed by miR-27a in glioma cells.

\section{Materials and methods}

Construction of short hairpin-expressing lentiviral vector. The short hairpin RNAs targeting miR-27a were cloned into the pGreenPuro ${ }^{\mathrm{TM}}$ shRNA expression lentivector (SBI). The hairpins were rationally designed for asymmetry such that the upper strand of the hairpin did not contain the miR-27a sequence, whereas the lower strand was fully complementary to miR-27a. The expression of the short hairpin was driven by the $\mathrm{H} 1$ promoter. This vector also encoded cop green fluorescence protein (copGFP) for the selection of stably transfected clones. Successful cloning was confirmed by sequencing. The pPACK-H1 Lentivector Packaging System (SBI) and the 293TN cell line (SBI) were used for the production of pseudoviral particles according to the manufacturer's instructions. U87 cells were then transduced at a multiplicity of infection (MOI) of 3 .

Cell culture and proliferation assay. The U87 human glioma cell line was obtained from the American Type Culture Collection (Manassas, VA, USA). The cells were maintained in DMEM (Invitrogen, Carlsbad, CA, USA), supplemented with $10 \%$ fetal bovine serum (Thermo Scientific), $100 \mathrm{U} / \mathrm{ml}$ penicillin and $100 \mu \mathrm{g} / \mathrm{ml}$ streptomycin (Invitrogen) at $37^{\circ} \mathrm{C}$ in a humidified atmosphere of $5 \% \mathrm{CO}_{2}$ and $95 \%$ air. Cell proliferation was measured by the colorimetric Cell Counting kit- 8 (CCK-8) assay (Dojindo). The transfected cells were plated at a density of 5,000 cells/well in 96 -well plates. After incubation for $2 \mathrm{~h}$ to allow cell attachment to the bottom of the well, $10 \mu \mathrm{l}$ CCK-8 solution were added to each well at 0,24 and $48 \mathrm{~h}$, and the plates were incubated for another $2 \mathrm{~h}$. The optical density was then determined at $450 \mathrm{~nm}$ using a microplate reader.

Cell cycle analysis. U87 cells were fixed with ice-cold $70 \%$ ethanol in phosphate-buffered saline, followed by incubation with $50 \mu \mathrm{g} / \mathrm{ml}$ propidium iodide, $3.8 \mathrm{mmol} / 1$ sodium citrate and $0.5 \mu \mathrm{g} / \mathrm{ml} \mathrm{RNase} \mathrm{A}$ at $4^{\circ} \mathrm{C}$ for $3 \mathrm{~h}$ and analyzed by flow cytometry.

Cell invasion assay. The invasive capacity of cells was determined using the BD BioCoat Matrigel invasion chambers $(8-\mu \mathrm{m}$ pores) (BD Biosciences). The transfected cells were seeded on the top chamber of each insert with complete medium added to the bottom chamber. After $48 \mathrm{~h}$, cells on the membrane were wiped off with a cotton swab. Fixed and stained with H\&E, cells on the underside of the membrane were counted from 4 microscope fields (magnification, $\mathrm{x} 200$ ). The mean number of invading or migrating cells was expressed as a percentage relative to the control.

Quantitation of miR-27a expression. Total RNA was isolated using TRIzol (Invitrogen) and cDNA was synthesized using the QuantiMir kit (SBI) following the manufacturer's instructions. Real-time PCR was performed with miR-27a-specific forward primer and universal reverse primer. Conditions for real-time
PCR were $50^{\circ} \mathrm{C}$ for $2 \mathrm{~min}, 95^{\circ} \mathrm{C}$ for $10 \mathrm{~min}, 40$ cycles of $95^{\circ} \mathrm{C}$ for $15 \mathrm{sec}$ and $60^{\circ} \mathrm{C}$ for $1 \mathrm{~min}$. Quantitative PCR was carried out using SYBR-Green JumpStart Taq ReadyMix (Sigma) and the 7300 Real-Time PCR Detection System (ABI). The results were analyzed using the comparative threshold cycle (CT) method.

Two-dimensional (2D) electrophoresis. The immobilized $\mathrm{pH}$ gradient (IPG) strip (pH 3-10, length $13 \mathrm{~cm}$; Bio-Rad, Hercules, CA, USA) was rehydrated with $1,500 \mu \mathrm{g}$ protein in $450 \mathrm{ml}$ rehydration buffer containing $7 \mathrm{M}$ urea, $2 \mathrm{M}$ thiourea, 4\% CHAPS, 65 mM DTT, 20 mM Trizma base, $1 \%$ IPG buffer and $0.002 \%$ bromophenol blue for $14 \mathrm{~h}$ at room temperature. Isoelectric focusing (IEF) was performed using the Protean IEF System (Bio-Rad) for a total of $70 \mathrm{kVh}$. The strip was then subjected to two-step equilibration in a buffer containing $6 \mathrm{M}$ urea, $20 \%$ glycerol, $2 \%$ SDS and $50 \mathrm{mM}$ Tris- $\mathrm{HCl}$ ( $\mathrm{pH} 8.8$ ), with $2 \% \mathrm{w} / \mathrm{v}$ DTT for the first step and $2.5 \% \mathrm{w} / \mathrm{v}$ iodoacetamide for the second step. The second-dimension SDS-PAGE (12\% T, 260x200x1.5 $\left.\mathrm{mm}^{3}\right)$ was carried out using a Mini-Protean 3 system (Amersham Biosciences, Piscataway, NJ, USA) according to the following procedures: $45 \mathrm{~min}$ at a constant power of $5 \mathrm{~W}$, followed by $20 \mathrm{~W} / \mathrm{gel}$ until the bromophenol blue front reached the bottom of the gel. Subsequently, the proteins in the gels were visualized using the Dodeca silver staining kit (Bio-Rad). The silver-stained protein 2D gels were scanned using an Amersham Biosciences Imagescanner and analyzed using ImageMaster 2D Elite v.6.0 (Amersham Biosciences).

In-gel digestion and matrix-assisted laser desorption/ionisation-time-of-flightmass spectrometry (MALDI-TOF-MS) identification. Protein spots were excised from gel with an operating knife blade and equilibrated in $50 \mathrm{mM} \mathrm{NH}_{4} \mathrm{HCO}_{3}$ to $\mathrm{pH}$ 8.0. After dehydrating with ACN and drying in $\mathrm{N}_{2}$ at $37^{\circ} \mathrm{C}$ for $20 \mathrm{~min}$, the gel pieces were rehydrated in $10 \mu \mathrm{l}$ trypsin solution $\left(12.5 \mathrm{ng} / \mu \mathrm{l}\right.$ in $\left.50 \mathrm{mM} \mathrm{NH}_{4} \mathrm{HCO}_{3}\right)$ at $4^{\circ} \mathrm{C}$ for $30 \mathrm{~min}$ and incubated at $37^{\circ} \mathrm{C}$ overnight. Peptides were extracted twice using $0.1 \%$ TFA in $30 \%$ CAN. The peptides were analyzed using Ultraflex II MALDI-TOF/TOF. Mass spectra were internally and externally calibrated with self-digested fragments of trypsin and standard peptides (Bruker, USA), respectively.

Protein identification and database searching. Protein identification using peptide mass fingerprinting (PMF) was performed by the Mascot search engine (http://www.matrixscience.com/; MatrixScience Ltd., London, UK) against the SwissProt protein database. The errors in peptide mass were in the range of $100 \mathrm{ppm}$. One missed tryptic cleavage site per peptide was allowed during the search. Proteins matching more than 4 peptides and with a Mascot score of $>64$ were considered significant $(\mathrm{P}<0.05) . \mathrm{MH}^{+}$was selected as the modification. Protein identification results were filtered with the GPS software.

miRNA target prediction. In order to define the potential targets of miR-27a, 4 publicly available computational algorithms, miRanda, miRWalk, RNA22 and TargetScan, were used. Targets commonly predicted by 2 or more algorithms were considered as putative targets of miR-27a. 


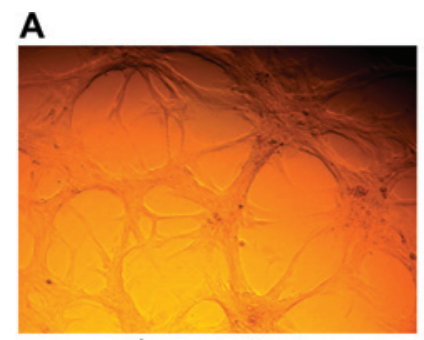

Phase contrast

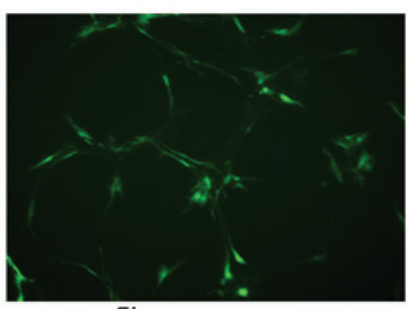

Fluorescence
B

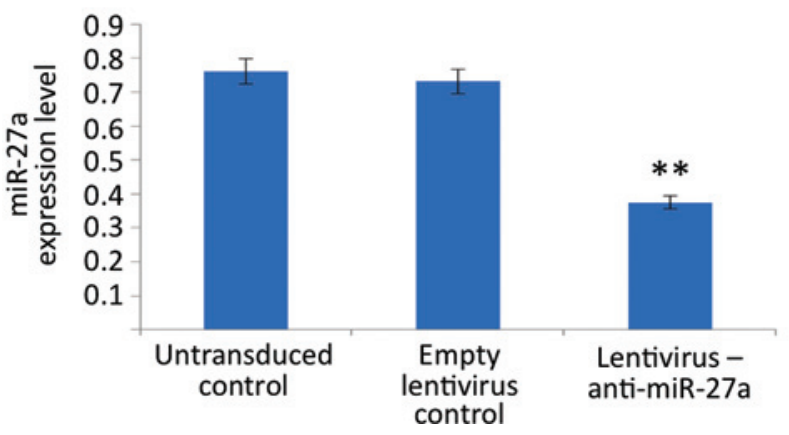

Figure 1. Stable lentiviral transduction of anti-miR-27a into U87 human glioma cells. (A) Transduction efficiency was determined by fluorescent microscopy after transduction with pGreenPuro $^{\mathrm{TM}}$ shRNA expression lentivector encoding anti-miR-27a and cop green fluorescence protein (copGFP) for $72 \mathrm{~h}$. Over $80 \%$ of transduced U87 cells showed green fluorescent signals. (B) The expression levels of endogenous miR-27a were determined by real-time PCR. The expression of anti-miR-27a was significantly reduced in U87 cells stably transduced with lentivirus encoding anti-miR-27a. ${ }^{* *} \mathrm{P}<0.01$, significantly different from both untransduced and empty lentivirus control groups.

Statistical analysis. The results are representative of multiple experiments and expressed as the means \pm SEM. Statistical analysis was performed with an analysis of variance (ANOVA) followed by the Turkey's t-test. P-values $<0.05$ denoted statistically significant differences.

\section{Results}

Stable lentiviral transduction of anti-miRNAs targeting miR-27a in U87 glioma cells. The lentivirus transduction efficiency of U87 glioma cells was determined by the detection of GFP signals by fluorescence microscopy at $72 \mathrm{~h}$ after transduction and confirmed to be $>80 \%$ (Fig. 1A). To select stably transduced cells, fluorescence-activated cell sorting was performed. After cell sorting, the miR-27a expression in stably transduced U87 cells was measured by real-time PCR. Fig. 1B demonstrates that the levels of miR-27a were significantly repressed in cells transduced with lentivirus stably expressing anti-miR-27a when compared to the control lentivirus-transduced cells or the untransduced cells.

Anti-miR-27a reduces the viability and increases apoptosis of U87 cells. To study the effect of the blockade of miR-27a on the proliferation of glioma cells, we examined changes in viable cell number by CCK-8 assays after transduction with anti-miR-27a-encoding lentiviral particles in U87 cells. The stable expression of anti-miR-27a significantly impaired the proliferation of U87 cells as indicated by the reduced viable cell number at the 24- and 48-h time-points when compared to the
A

$\square$ Untransduced control

Empty lentivirus control

- Lentivirus - anti-miR-27a

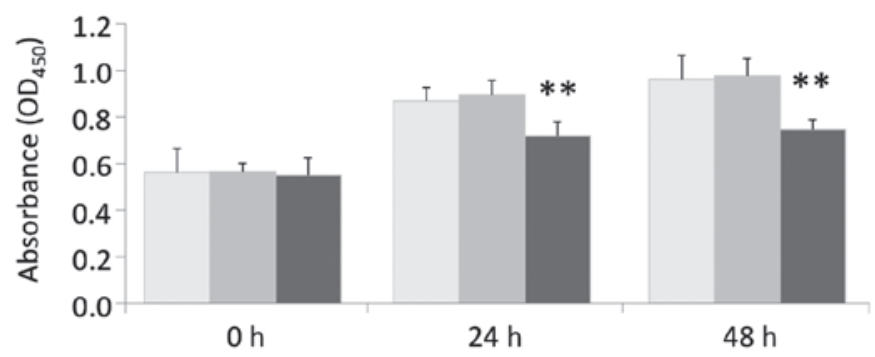

B

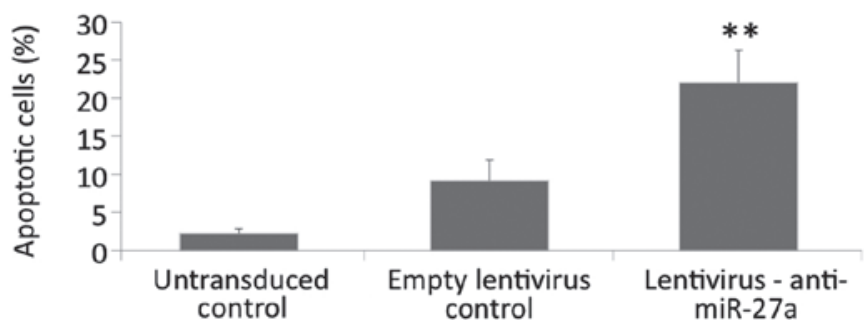

Figure 2. Effects of anti-miR-27a on proliferation and apoptosis of U87 glioma cells. (A) The effect of stable transduction of anti-miR-27a on U87 cell proliferation was determined by the colorimetric Cell Counting kit-8 (CCK-8) assay. Anti-miR-27a significantly impaired the cell proliferation of U87. (B) Apoptotic cells with DNA fragmentation were quantitated as a proportion of the cells in the sub-G1 phase by flow cytometry. Expression of anti-miR-27a substantially induced apoptotic cell death. ${ }^{* *} \mathrm{P}<0.01$, significantly different from both untransduced and empty lentivirus control groups.

untransduced control or cells transduced with the control lentiviral particles (Fig. 2A). At the 48-h time-point, the viable cell number was significantly reduced by $16.5 \%$ when compared to the control lentivirus-transduced group. To further confirm the anti-proliferative action of anti-miR-27a, cell cycle analysis by flow cytometry was performed. The results showed that the stable expression of anti-miR-27a induced a substantial accumulation of U87 cells at the sub-G1 phase without affecting the distribution of other phases of the cell cycle, suggesting that miR-27a inhibition may cause apoptotic cell death in U87 cells (Fig. 2B).

Anti-miR-27a reduces invasiveness of U87 cells. To investigate the effect of anti-miR-27a expression on cell invasiveness, Transwell invasion assay was performed using a chamber coated with a thin layer of extracellular matrix. The results showed that the stable expression of anti-miR-27a substantially reduced the invasiveness of U87 glioma cells, as indicated by a marked decrease in the number of invaded cells (Fig. 3).

Target identification by 2D-gel electrophoresis/mass spectrometry. To determine the change in protein profile in response to $\mathrm{miR}-27 \mathrm{a}$ inhibition, gel-based comparative proteomic analysis was performed. As shown in Fig. 4, 29 protein spots were found to be significantly altered in the cells stably expressing anti-miR-27a as compared to the control lentivirus-transduced group, among which 13 and 16 proteins were found to be significantly downregulated and upregulated, respectively. Most of the protein spots of interest were 

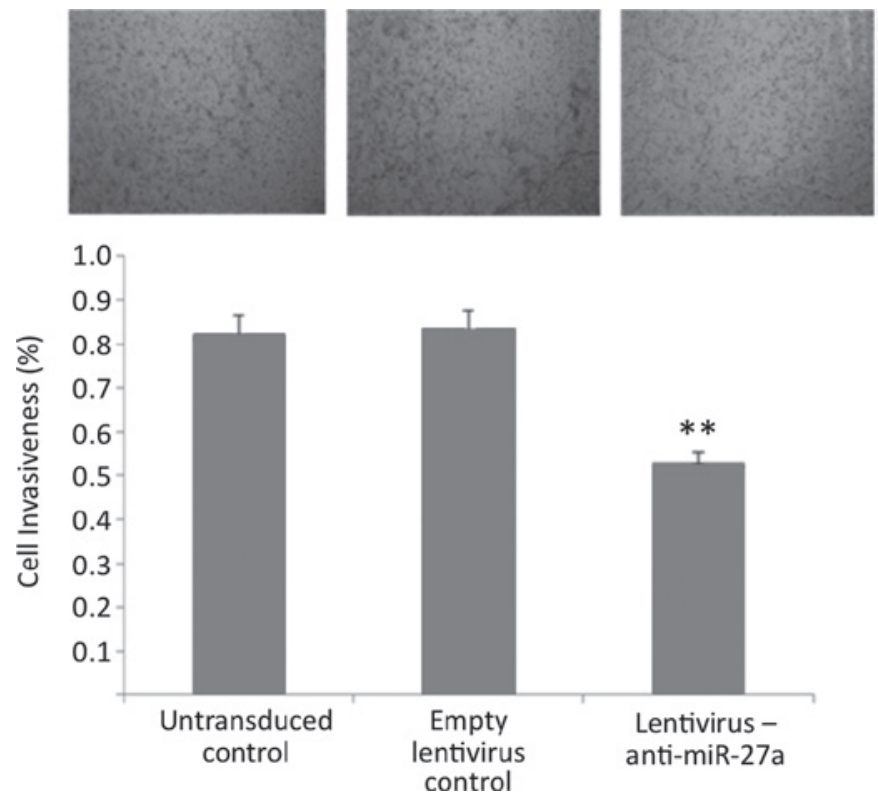

Figure 3. Effect of anti-miR-27a on the invasiveness of U87 glioma cells was determined by Matrigel Transwell assays. Micrographs were shown to indicate the number of cells invaded through the Matrigel membrane from upper chambers to lower chambers in different treatment groups. ${ }^{* *} \mathrm{P}<0.01$, significantly different from both untransduced and empty lentivirus control groups.

successfully identified by MALDI-TOF MS and by subsequent comparative sequence search in the Mascot database (Table I). Among the 16 upregulated proteins, the mRNAs of 8 proteins were predicted by at least 2 out of 4 computational algorithms to be the direct targets of miR-27a.

\section{Discussion}

miRNA dysregulation plays an active role in cancer development. In this regard, miR-27a, an oncogenic miRNA overexpressed in many types of cancer, has been reported to promote cell proliferation (19), oncogene-induced transformation (23), metastasis (24) and multidrug resistance (25). miR-27a has also been implicated in the regulation of apoptosis (26), angiogenesis (18) and hormone sensitivity (27). The antagonism of miR-27a function thus represents a novel approach for the treatment of cancer. In the present study, we demonstrate that the inhibition of miR-27a by the stable expression of anti-miRNA significantly suppresses the proliferation and invasiveness of U87 glioma cells. Although miR-27a has been shown to be abundantly expressed in glioma tissues (22), this is the first study to demonstrate the influence of miR-27a on the malignant phenotypes of glioma cells.

miRNA performs its biological functions by repressing the protein translation and/or inducing the degradation of its mRNA targets. To date, a number of genes, including Fas associated protein with death domain (FADD) (26), zinc finger and BTB domain containing 10 (ZBTB10; a Sp1 repressor) (28), Ring1 and YY1 binding protein (RYBP; an apoptotic facilitator) (28), Myt-1 (a cdc2 inhibitor) (18), Forkhead box protein O1 (FOXO1) (29), homeodomain-interacting protein kinase-2 (HIPK2) (30), Sprouty2 (21), prohibitin (19) and F-box/WD repeat-containing protein 7 (Fbxw7) (23), have been identified to be the targets of miR-27a. In the current

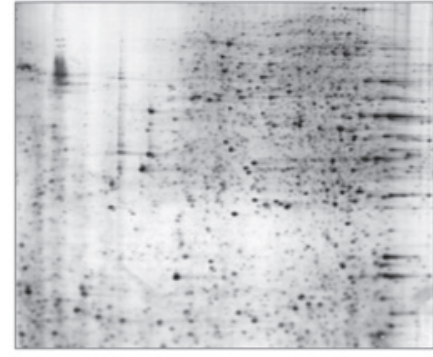

Untransduced control

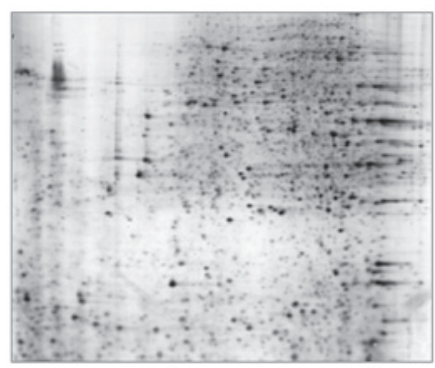

Empty lentivirus control

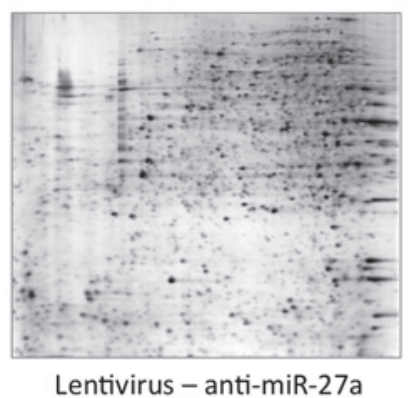

Figure 4. Differential protein expression was determined by comparative gel-based proteomics. Proteins were resolved by isoelectric focusing (IEF) (pH 3-10) in the first dimension (horizontal) followed by SDS-PAGE in the second dimension (vertical). Differentially expressed proteins are shown as black points.

study, we hypthesized that the repressing effects of miR-27a on its targets would be relieved through the stable expression of anti-miR-27a, leading to the upregulation of its targets. By the gel-based comparative proteomic approach, we identified 16 proteins that were upregulated by more than 10 -fold in anti-miR-27a-expressing U87 cells. Using multiple computational algorithms, 8 of these upregulated proteins, including the RAD50 homolog, protein disulfide isomerase family A member 5 (PDIA5), dihydropyrimidinase-like 2 (DPYSL2), A kinase anchor protein 4 (AKAP4), lamin A, PRP19/PSO4 pre-mRNA processing factor 19 homolog (PRPF19), septin 11 and enolase 1, were predicted to be the targets of miR-27a in glioma cells. These findings suggest that the combined use of bioinformatic and proteomic approaches may be an efficient method for the identification of novel miRNA targets.

Some of the newly identified proteins putatively targeted by miR-27a have been implicated in cancer biology. For instance, both the RAD50 homolog and PRPF19 have been shown to mediate DNA repair and to have an impact on cell cycle and apoptosis $(31,32)$. The loss of lamin A has also frequently been observed during tumor progression and may contribute to the disruption of nuclear architecture and chromatin structure, thereby increasing genetic instability (33). Moreover, the 


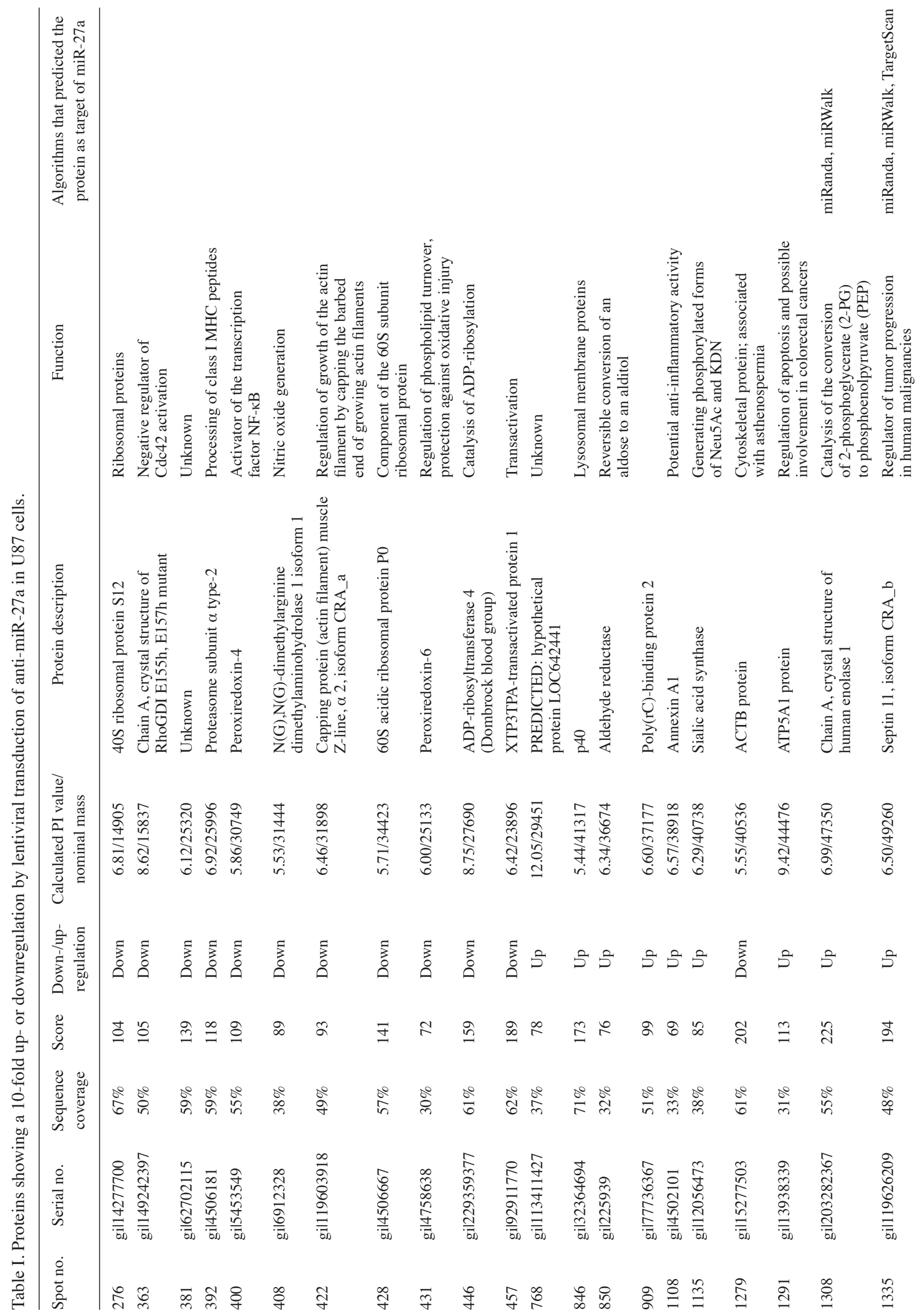


expression of DPYSL2 has been reported to be reduced in carcinogen-exposed murine lung tissue (34). Septins, a family of cytoskeleton-related proteins dysregulated in cancer, are also involved in cytokinesis, chromosome segregation, DNA repair, migration and apoptosis, all of which are important to cancer development (35). In addition, glioma tissues have been found to possess lower enolase activity than normal brain tissues (36). The mechanism by which the orchestrated expression of these proteins mediates the anticancer effect of anti-miR-27a in glioma cells, however, warrants further investigation.

Lentiviral vectors are promising for gene therapy applications due to their ability to sustain long-term transgene expression (37). In this study, we demonstrate that the lentiviral vector may be used to deliver specific anti-miRNAs to glioma cells and impair their growth and invasiveness. Since 2002, a number of trials using lentiviral vectors for the treatment of both infectious and genetic diseases have been carried out (37). Our study provides in vitro evidence that the lentiviral vector may be used to stably express anti-miRNAs in glioma cells. With the advance of tissue-specific expression control and further understanding of miRNA dysregulation in gliomas, we anticipate that the anti-miRNA-encoding lentivirus will become the latest addition to the armamentarium to fight against gliomas in humans in the near future.

\section{Acknowledgements}

This study was supported by the Jiangsu Natural Scientific Fund (SBK200921106) and by the Yangtz River Scholar and Innovation Research Team Development Program (Project no. IRT0945).

\section{References}

1. Westphal M and Lamszus K: The neurobiology of gliomas: from cell biology to the development of therapeutic approaches. Nat Rev Neurosci 12: 495-508, 2011.

2. Hatanpaa KJ, Burma S, Zhao D and Habib AA: Epidermal growth factor receptor in glioma: signal transduction, neuropathology, imaging, and radioresistance. Neoplasia 12: 675-684, 2010.

3. Yan H, Parsons DW, Jin G, McLendon R, Rasheed BA, Yuan W, Kos I, Batinic-Haberle I, Jones S, Riggins GJ, et al: IDH1 and IDH2 mutations in gliomas. New Eng J Med 360: 765-773, 2009.

4. Endersby R and Baker SJ: PTEN signaling in brain: neuropathology and tumorigenesis. Oncogene 27: 5416-5430, 2008.

5. Giannopoulos S and Kyritsis AP: Diagnosis and management of multifocal gliomas. Oncology 79: 306-312, 2010.

6. Wurdinger T, Tannous BA, Saydam O, Skog J, Grau S, Soutschek J, Weissleder R, Breakefield XO and Krichevsky AM: miR-296 regulates growth factor receptor overexpression in angiogenic endothelial cells. Cancer Cell 14: 382-393, 2008.

7. Wu WK, Law PT, Lee CW, Cho CH, Fan D, Wu K, Yu J and Sung JJ: MicroRNA in colorectal cancer: from benchtop to bedside. Carcinogenesis 32: 247-253, 2011.

8. Wu WK, Lee CW, Cho CH, Fan D, Wu K, Yu J and Sung JJ: MicroRNA dysregulation in gastric cancer: a new player enters the game. Oncogene 29: 5761-5771, 2010.

9. Baraniskin A, Kuhnhenn J, Schlegel U, Maghnouj A, Zollner H, Schmiegel W, Hahn S and Schroers R: Identification of microRNAs in the cerebrospinal fluid as biomarker for the diagnosis of glioma. Neuro Oncol 14: 29-33, 2012.

10. Chan JA, Krichevsky AM and Kosik KS: MicroRNA-21 is an antiapoptotic factor in human glioblastoma cells. Cancer Res 65: 6029-6033, 2005. 
11. Quintavalle C, Garofalo M, Zanca C, Romano G, Iaboni M, Del Basso De Caro M, Martinez-Montero JC, Incoronato M, Nuovo G, Croce CM and Condorelli G: miR-221/222 overexpession in human glioblastoma increases invasiveness by targeting the protein phosphate PTPmu. Oncogene 31: 858-868, 2012.

12. Kefas B, Godlewski J, Comeau L, Li Y, Abounader R, Hawkinson M, Lee J, Fine H, Chiocca EA, Lawler S and Purow B: microRNA-7 inhibits the epidermal growth factor receptor and the Akt pathway and is down-regulated in glioblastoma. Cancer Res 68: 3566-3572, 2008

13. Li KK, Pang JC, Ching AK, Wong CK, Kong X, Wang Y, Zhou L, Chen Z and Ng HK: miR-124 is frequently down-regulated in medulloblastoma and is a negative regulator of SLC16A1. Hum Pathol 40: 1234-1243, 2009.

14. Godlewski J, Nowicki MO, Bronisz A, Williams S, Otsuki A Nuovo G, Raychaudhury A, Newton HB, Chiocca EA and Lawler S: Targeting of the Bmi-1 oncogene/stem cell renewal factor by microRNA-128 inhibits glioma proliferation and selfrenewal. Cancer Res 68: 9125-9130, 2008.

15. Silber J, Lim DA, Petritsch C, Persson AI, Maunakea AK, Yu M, Vandenberg SR, Ginzinger DG, James CD, Costello JF, et al: $\mathrm{miR}-124$ and miR-137 inhibit proliferation of glioblastoma multiforme cells and induce differentiation of brain tumor stem cells. BMC Med 6: 14, 2008

16. Shi L, Cheng Z, Zhang J, Li R, Zhao P, Fu Z and You Y: hsa-mir181a and hsa-mir-181b function as tumor suppressors in human glioma cells. Brain Res 1236: 185-193, 2008

17. Ciafre SA, Galardi S, Mangiola A, Ferracin M, Liu CG, Sabatino G, Negrini M, Maira G, Croce CM and Farace MG: Extensive modulation of a set of microRNAs in primary glioblastoma. Biochem Biophys Res Commun 334: 1351-1358, 2005.

18. Mertens-Talcott SU, Chintharlapalli S, Li X and Safe S: The oncogenic microRNA-27a targets genes that regulate specificity protein transcription factors and the G2-M checkpoint in MDA-MB-231 breast cancer cells. Cancer Res 67: 11001-11011, 2007.

19. Liu T, Tang H, Lang Y, Liu M and Li X: MicroRNA-27a functions as an oncogene in gastric adenocarcinoma by targeting prohibitin. Cancer Lett 273: 233-242, 2009

20. Chintharlapalli S, Papineni S, Abdelrahim M, Abudayyeh A, Jutooru I, Chadalapaka G, Wu F, Mertens-Talcott S, Vanderlaag K, Cho SD, Smith R III and Safe S: Oncogenic microRNA-27a is a target for anticancer agent methyl 2-cyano-3,11-dioxo-18betaolean-1,12-dien-30-oate in colon cancer cells. Int J Cancer 125 $1965-1974,2009$.

21. Ma Y, Yu S, Zhao W, Lu Z and Chen J: miR-27a regulates the growth, colony formation and migration of pancreatic cancer cells by targeting Sprouty2. Cancer Lett 298: 150-158, 2010.

22. Skog J, Wurdinger T, van Rijn S, Meijer DH, Gainche L, Sena-Esteves M, Curry WT Jr, Carter BS, Krichevsky AM and Breakefield XO: Glioblastoma microvesicles transport RNA and proteins that promote tumour growth and provide diagnostic biomarkers. Nat Cell Biol 10: 1470-1476, 2008.
23. Wang Q, Li DC, Li ZF, Liu CX, Xiao YM, Zhang B, Li XD, Zhao J, Chen LP, Xing XM, et al: Upregulation of miR-27a contributes to the malignant transformation of human bronchial epithelial cells induced by SV40 small T antigen. Oncogene 30: 3875-3886, 2011.

24. Katada T, Ishiguro H, Kuwabara Y, Kimura M, Mitui A, Mori Y, Ogawa R, Harata K and Fujii Y: microRNA expression profile in undifferentiated gastric cancer. Int J Oncol 34: 537-542, 2009.

25. Zhu H, Wu H, Liu X, Evans BR, Medina DJ, Liu CG and Yang JM: Role of MicroRNA miR-27a and miR-451 in the regulation of MDR1/P-glycoprotein expression in human cancer cells. Biochem Pharmacol 76: 582-588, 2008.

26. Chhabra R, Adlakha YK, Hariharan M, Scaria V and Saini N: Upregulation of miR-23a-27a-24-2 cluster induces caspasedependent and -independent apoptosis in human embryonic kidney cells. PloS One 4: e5848, 2009.

27. Li X, Mertens-Talcott SU, Zhang S, Kim K, Ball J and Safe S: MicroRNA-27a indirectly regulates estrogen receptor $\{$ alpha\} expression and hormone responsiveness in MCF-7 breast cancer cells. Endocrinology 151: 2462-2473, 2010.

28. Scott GK, Mattie MD, Berger CE, Benz SC and Benz CC: Rapid alteration of microRNA levels by histone deacetylase inhibition. Cancer Res 66: 1277-1281, 2006.

29. Guttilla IK and White BA: Coordinate regulation of FOXO1 by miR-27a, miR-96, and miR-182 in breast cancer cells. J Biol Chem 284: 23204-23216, 2009.

30. Li Z, Hu S, Wang J, Cai J, Xiao L, Yu L and Wang Z: MiR-27a modulates MDR1/P-glycoprotein expression by targeting HIPK2 in human ovarian cancer cells. Gynecol Oncol 119: 125-130, 2010.

31. Abuzeid WM, Jiang X, Shi G, Wang H, Paulson D, Araki K, Jungreis D, Carney J, O'Malley BW Jr and Li D: Molecular disruption of RAD50 sensitizes human tumor cells to cisplatinbased chemotherapy. J Clin Invest 119: 1974-1985, 2009.

32. Lu X and Legerski RJ: The Prp19/Pso4 core complex undergoes ubiquitylation and structural alterations in response to DNA damage. Biochem Biophys Res Commun 354: 968-974, 2007.

33. Gonzalez-Suarez I, Redwood AB and Gonzalo S: Loss of A-type lamins and genomic instability. Cell Cycle 8: 3860-3865, 2009.

34. Bortner JD Jr, Das A, Umstead TM, Freeman WM, Somiari R, Aliaga C, Phelps DS and El-Bayoumy K: Down-regulation of 14-3-3 isoforms and annexin A5 proteins in lung adenocarcinoma induced by the tobacco-specific nitrosamine NNK in the $\mathrm{A} / \mathrm{J}$ mouse revealed by proteomic analysis. J Proteome Res 8: 4050-4061, 2009.

35. Connolly D, Abdesselam I, Verdier-Pinard P and Montagna C: Septin roles in tumorigenesis. Biol Chem 392: 725-738, 2011.

36. Joseph J, Cruz-Sanchez FF and Carreras J: Enolase activity and isoenzyme distribution in human brain regions and tumors. J Neurochem 66: 2484-2490, 1996.

37. D'Costa J, Mansfield SG and Humeau LM: Lentiviral vectors in clinical trials: current status. Curr Opin Mol Ther 11: 554-564, 2009. 